\title{
The physiological consequences of varied heat exposure events in adult Myzus persicae: a single prolonged exposure compared to repeated shorter exposures.
}

\author{
Behnaz Ghaedi ${ }^{\text {Corresp., }}{ }^{1}$, Nigel R Andrew ${ }^{1}$ \\ ${ }^{1}$ Centre for Behavioural and Physiological Ecology, Zoology, University of New England, Armidale, NSW, Australia \\ Corresponding Author: Behnaz Ghaedi \\ Email address: ghaedi.b@gmail.com
}

The study of environmental stress tolerance in aphids has primarily been at low temperatures. In these cases, and in the rare cases of high temperature tolerance assessments, all exposures had been during a single stress event. In the present study, we examined the physiological consequences of repeated high temperature exposure with recovery periods between these stress events in Myzus persicae. We subjected individuals to either a single prolonged three hour heating event, or three one hour heating events with a recovery time of 24 hours between bouts. Aphids exposed to repeated bouts of high temperatures had more glucose and higher expression of proteins and osmolyte compounds, such as glycerol, compared to the prolonged exposure group. However, aphids exposed to the repeated high temperature treatment had reduced sources of energy such as trehalose and triglyceride compounds than the prolonged exposure group. Recovery time had more physiological costs (based on production of more protein and consumption of more trehalose and triglyceride) and benefits (based on production of more osmolytes) in repeated high temperature treatments. As aphids are known to respond differently to constant versus 'natural' fluctuating temperature regimes, conclusions drawn from constant temperature data sets may be problematic. We suggest future experiments assessing insect responses to thermal stress incorporate a repeated stress and recovery pattern into their methodologies. 
1 The physiological consequences of varied heat exposure events in adult Myzus persicae: a 2 single prolonged exposure compared to repeated shorter exposures.

3

4 Behnaz Ghaedi ${ }^{1 *}$, Nigel R Andrew ${ }^{1}$

$5{ }^{1}$ Centre for Behavioural and Physiological Ecology, Zoology, University of New England, Armidale, 6 NSW, 2351, Australia.

7 Corresponding Author:

8 Behnaz Ghaedi

9 Email address: ghaedi.b@gmail.com 


\section{The physiological consequences of varied heat exposure events in adult Myzus persicae: a single prolonged exposure compared to repeated shorter exposures.}

Running title: Heat exposure and associated metabolic changes

Authors: Behnaz Ghaedi ${ }^{1 *}$, Nigel R Andrew ${ }^{1}$

${ }^{1}$ Centre for Behavioural and Physiological Ecology, Zoology, University of New England, Armidale, NSW, 2351, Australia.

*Author for correspondence (Ghaedi.b@gmail.com)

\section{Abstract}

The study of environmental stress tolerance in aphids has primarily been at low temperatures. In these cases, and in the rare cases of high temperature tolerance assessments, all exposures had been during a single stress event. In the present study, we examined the physiological consequences of repeated high temperature exposure with recovery periods between these stress events in Myzus persicae. We subjected individuals to either a single prolonged three hour heating event, or three one hour heating events with a recovery time of 24 hours between bouts. Aphids exposed to repeated bouts of high temperatures had more glucose and higher expression of proteins and osmolyte compounds, such as glycerol, compared to the prolonged exposure group. However, aphids exposed to the repeated high temperature treatment had reduced sources of energy such as trehalose and triglyceride compounds than the prolonged exposure group. Recovery time had more physiological costs (based on production of more protein and consumption of more trehalose and triglyceride) and benefits (based on production of more osmolytes) in repeated high temperature treatments. As aphids are known to respond differently to constant versus 'natural' fluctuating temperature regimes, conclusions drawn from constant temperature data sets may be problematic. We suggest future experiments assessing insect responses to thermal stress incorporate a repeated stress and recovery pattern into their methodologies.

Keywords: Metabolite, heat exposure, aphid, thermal tolerance, repeated heating 


\section{Introduction}

Climate change is one of the most critical threats to biodiversity (Dawson et al., 2011; IPCC., 2014). Human-induced climate change is predicted to increase the frequency of climatic extremes (e.g. heat waves and severe droughts or floods), climatic variability (Lean and Rind, 2008; Rahmstorf and Coumou, 2011) and mean of the thermal environment in regions around the world (Niehaus et al., 2012). Global mean temperature has risen by $0.85^{\circ} \mathrm{C}$ from 1880 to 2012 . All of the warmest 20 years on record have occurred since 1990 (CSIRO-ABM, 2014).

Exposure to different thermal means and variability can have a substantive influence on animal physiological performance (Huey et al., 2012). This may include a modification of performance curve parameters including two critical fitness-influencing components: the upper critical temperature and the thermal optimum (Angilletta, 2009). All insects keep their physiological performance within a specific range of temperatures, and many of their physiological functions may be reduced when exposed to extreme temperatures (Mironidis and Savopoulou-Soultani, 2010). An important aspect of habitat quality is minimal exposure to extreme thermal stress (Huey, 1991). In terrestrial habitats, climate change is strengthening fluctuations and amplitude of temperature variation, which will lead to prolonged adverse temperature exposure in terresterial habitats (Sinclair et al., 2006; Andrew, 2013; Vasseur et al., 2014).

Critical temperature responses can shift somewhat based on an animals environmental thermal experience (Somero, 2010). As insects are ectotherms, their survival, population dynamics, and distribution are influenced by temperature (Chown et al., 2010; Bauerfeind and Fischer, 2014). Therefore investigating impacts of temperature variation on an individual's performance and understanding these plastic responses of populations to temperature is critical (Pörtner et al., 2006); and may have implications for their potential responses to climate change.

84 Some aphid species, including $M$. persicae, are distributed widely across the globe. The cabbage aphid, Brevicoryne brassicae (L.), the turnip aphid, Lipaphis erysimi Kalt, and the green peach aphid, Myzus persicae (Sulzer) (Hemiptera: Aphidae) are the three major aphid pests infesting 
87 canola in Australia (Gu et al., 2007; Gia and Andrew, 2015). Myzus persicae (green peach aphid) is known to transmit over 100 phytopathogenic viruses among 50 different plant families. Many of its hosts include major crops (e.g. sugar beet, beans, brassicas, potatoes, citrus) and on a world wide scale this species is regarded as the most important aphid pest (Blackman and Eastop, 1984). Green peach aphid host alternating between the primary peach Prunus persica host in winter and various herbaceous hosts, belonging to 50 different families, which include brassicas, potatoes and sugar beet, in summer (Blackman and Eastop, 2000)

Extreme climatic events such as heat waves and daily fluctuations can impact aphids in various ways: reducing fecundity and population growth; slowing development; and can also affect community structure and interrupt trophic cascades through effects on performance of individual species and through changes in the strength of interactions between them (Davis et al., 2006; Gillespie et al., 2012; Zhao et al. 2014; Colinet et al. 2015). Aphids are more sensitive to acute changes in temperature rather than the duration of extreme temperature exposure, and nymphs do not experience diapause (Davis et al., 2006), making them a suitable test organism for our study. Studying the effects of climate change on aphids is complex. Many organisms that live in fluctuating thermal environments, such as aphids, display a high degree of thermal plasticity in their response to changing conditions, and have a greater resilience in their ability to recover from ecological perturbations (Davis et al., 2006). In order to understand how aphids perform in a warming climate it is necessary to consider both exposure temperature and exposure duration with or without recovery time.

In responding to extreme environmental conditions, insects rely on a combination of different factors: such as molecular processes (gene expression, heat shock proteins, and enzymes); changes in membrane structure; and osmolyte compounds; to survive and recover from unfavourable conditions (Back et al., 1979; Henle et al., 1983; Lin et al., 1984; Kim and Lee, 1993; Meng et al., 2004; Wang et al., 2006; Clark and Worland, 2008; Tollarová-Borovanská et al., 2009). Aphids and whiteflies were one of the first insect taxa reported to accumulate polyols in response to high temperatures and also reveal that these compounds could stabilize proteins structure against thermal denaturation (Back et al., 1979). Whole-animal respiration will change when exposed to repeated stress (Lalouette et al., 2011; Yocum et al., 2011) and understanding 
118 the implications of this is critical as this will impact on animal survival and body maintenance as

119 changes occur in energy and water usage (Schimpf et al., 2009; Chown et al., 2011). In addition, 120 the upper critical temperature threshold at which an animal loses muscular control $\left(\mathrm{CT}_{\max }\right)$ is a

121 metric of interest as it is useful in predicting phenotypic effects of warming (Huey et al., 2012).

122 Using laboratory estimates of thermal tolerance enables the seasonal abundance and geographic 123 distribution of organisms to be determined (Ju et al., 2013).

125 It has become clear that constant temperatures are not useful for study performance thermal

126

127

128

129

130

131

132

133

134

135

136

137

138

139

140

141

142

143

144

145

146

147

response of organisms as they do not mimic the fluctuating temperature conditions which occur within the natural environment (Lamb, 1961; Davis et al., 2006). Constant temperature conditions also underestimate thermal thresholds of individuals and become less accurate compared to fluctuating temperature regimes (Davis et al., 2006; Niehaus et al., 2012). This implies that fluctuating temperature experiments ought to be "normal" while constant temperature insect development studies were "abnormal" experimental conditions (CloudsleyThompson, 1953). Fluctuating temperatures enhanced resistance of leaf beetles and fruit-flies to low temperature (Casagrande and Haynes, 1976; Meats, 1976) and that fitness could be more significant in repeated temperatures (Beardmore and Levine, 1963).

In previous studies much attention has focused on the cold tolerance of Myzus persicae (O’doherty and Bale, 1985; Bale et al., 1988; Clough et al., 1990; Howling et al., 1994; Bezemer et al., 1998; Vorburger, 2004) as well as assessments of the effects of temperature on physiological parameters including their thermal tolerance at different latitudes and altitudes (Bezemer et al., 1998; Alford et al., 2012a). There is a paucity of knowledge regarding how aphid physiology is affected by repeated exposure to high temperatures. Here, we assessed aphid metabolic rates after different heating regimes (a single prolonged exposure and repeated shortterm exposure with recovery time, and no heat exposure) using flow-through respirometry; we also assessed the upper critical temperature threshold, energy reserves and their osmolyte compound profile, as indicators of aphid stress response after exposure to the different heating regimes. 
148 We predict that repeated short-term exposure to high temperatures will increase adult aphid 149 thermal tolerance, as recovery time between heat stress bouts will enable metabolic and cellular 150 repairs to occur (Storey and Storey, 2004). We also predict that aphids will accumulate polyols 151 and sugars in response to high temperatures (Hendrix and Salvucci, 1998) which will result in an 152 increased $\mathrm{CT}_{\max }$.

\section{Methods and Materials}

154 Aphids and Diet Chamber Construction

155 Stock colonies of Myzus persicae (green peach aphid), were collected from canola plants at the 156 Laureldale Farm property (University of New England, Armidale, NSW Australia) in 2013.

157 The lab colony were established from an isofemale line (BG_13-001) and maintained on canola 158 variety 'Thunder Bay' plants in a glasshouse with $25 \pm 0.5^{\circ} \mathrm{C}$ temperatures, $65 \%$ relative 159 humidity, under a 16:8 h (L: D) photoperiod provided by fluorescent lamp for two years to 160 ensured continuous apomictic parthenogenesis.

161 Since aphids have parthenogenetic embryogenesis (Dixon, 2005) we bred three generations of aphids in the lab to reduce maternal and grand maternal affects: we removed the wingless female adult aphids after 3 days, then the resulting nymphs were left for seven days and we continued this process for three generations. The third generation resulting nymphs were housed at $25^{\circ} \mathrm{C}$, $65 \%$ relative humidity, under a $16: 8 \mathrm{~h}(\mathrm{~L}: \mathrm{D})$ in a Thermoline incubator $(\mathrm{TRH}-300)$ prior to experimental manipulation.

\section{Diet cage preparation}

169 To rear our aphids on artificial diets we used diet cages. Diet cages were constructed from rigid 170 clear PVC plastic tubing with a $12 \mathrm{~cm}$ diameter (Fig 1). A $7 \mathrm{~cm} \mathrm{x} 7 \mathrm{~cm}$ square of parafilm was 171 extended by force across the top of a cage, and $2 \mathrm{ml}$ of artificial diet was pipetted on top of the 172 parafilm layer. A second $7 \mathrm{~cm} \times 7 \mathrm{~cm}$ sheet of parafilm was then extended over the first sheet, 173 forcing diet across the top surface of the cage, but avoiding leakage over the edge. Then by using 174 a paintbrush, aphids were placed on the underside of the parafilm. The diet cages where then put 
175 into a closed transparent box $(30 \times 30 \mathrm{~cm})$ and put into the incubator prior to the application of 176 treatments.

\section{Artificial Diet}

178 The artificial diet used to rear the aphids was based on work by Douglas (1988) and consisted of 179 specific concentrations of phosphate, vitamins, and minerals (Table 1). In the experiments, four 180 replicate groups of 200 larval aphids were maintained on the test diet for 5 days (i.e. from one to 1816 days of age). The specified amounts of each component (see Table 1) were prepared with 182 distilled deionized water to the total volume of $10 \mathrm{ml}$ in a glass container. The $\mathrm{pH}$ of the solution 183 was 7.0-7.5. The diet solution was divided into $2 \mathrm{ml}$ aliquots, and stored at $4^{\circ} \mathrm{C} \mathrm{s}$ for less than 1 184 week or at $-20^{\circ} \mathrm{C}$ for less than 3 months. In all experiments, distilled deionized water was used 185 in all of the solutions and the diets of the aphids were changed twice a week for the duration of 186 our study.

\section{Experimental Conditions}

188 To investigate the effects of fluctuating thermal regimes (FTR), the experimental design was a 189 simplified version of the experimental protocol of Marshall and Sinclair (2011) and Zhang et al.

190 (2011). For the repeated heat stress exposure treatment, adult aphids were exposed to one to 191 three diurnal cycles (We left them in the food diet and put them into the incubator) of $1 \mathrm{~h}$ at $38^{\circ} \mathrm{C}$ 192 (we didn't control $\mathrm{RH}$ ) followed by $24 \mathrm{~h}$ at $25^{\circ} \mathrm{C}, 65 \%$ relative humidity (RH). Adult aphids 193 (seven day old individuals) from the third generation reared on the artificial diet were used. For 194 the single prolonged heat exposure treatment, separate groups of adults were exposed to $38^{\circ} \mathrm{C}$ for $1953 \mathrm{~h}$, to make total heat exposure time equivalent among treatments. Post treatment, this group 196 were also given a $24 \mathrm{~h}$-period of recovery at $25^{\circ} \mathrm{C}, 65 \% \mathrm{RH}$. Meanwhile, control animals were 197 held at $25^{\circ} \mathrm{C}, 65 \% \mathrm{RH}$ for the duration of the study.

198 Estimates for the upper critical temperature threshold limits for M. persicae have previously 199 found to range from $38.5^{\circ} \mathrm{C}$ (Broadbent and Hollings, 1951) to $42^{\circ} \mathrm{C}$ (Hazell et al., 2010). Myzus 200 persicae are known to survive $1 \mathrm{~h}$ per day above their $\mathrm{CT}_{\max }$ of $38.5^{\circ} \mathrm{C}$ (Davis et al., 2006) and so 201 the FTR was chosen to fluctuate around a value close to their $\mathrm{CT}_{\max }$. In general, upper 202 temperatures are difficult to experiment with compared to lower temperatures because their 203 performance curve optima is very close to $\mathrm{CT}_{\text {max }}$. A test temperature of $38^{\circ} \mathrm{C}$ was chosen as there 204 was $60-70 \%$ survival following the prolonged thermal exposure for 3 hours. 


\section{Quantification of Metabolic Reserves}

206 Twenty-four hours after a heat exposure (Figure 2), four replicate groups of adult aphids were

207

208

209

210

211

212

213

214

215

216

217

218

219

220

221

222

223

224

225

226

227

228

229

230

231

232

233

234

235

weighed to $0.001 \mathrm{mg}$ on a Mettler Toledo XP2U (Switzerland) electronic balance, then homogenized in $80 \mu$ lextraction buffer (35mM Tris, $25 \mathrm{mM} \mathrm{KCl,} 10 \mathrm{mM} \mathrm{MgCl2}$, pH 7.5) with $0.1 \%(\mathrm{v} / \mathrm{v})$ Triton-X-100 after centrifuging for 1 minute at $13,000 \mathrm{rpm}$ at $4{ }^{\circ} \mathrm{C}$. Supernatant was then removed and placed in a new tube which was then stored at $-20^{\circ} \mathrm{C}$ until all assays were conducted.

The assay kits :used included the Sigma triglyceride and glycerol assay kit (Sigma Triglyceride (Sigma:T2449), Free glycerol reagent (Sigma:F6428), Glycerol stock - Sigma:G7793-5 ml at 2.5 $\mathrm{mg} / \mathrm{ml})$ ); the BioRad Coomassie Brilliant Blue microassay method (500-0201), with bovine serum albumin as standard (40-480 mg protein ) for protein; and the Sigma glucose assay kit for glucose (Product Code GAGO-20, contains 500 units of glucose oxidase, O-Dianisidine Reagent (Product Code D 2679)) and following trehalose measurement (Porcine Kidney Trehalase (Sigma:T8778) and 0.2 M sodium citrate (5.882 g/100ml), $1 \mathrm{mM}$ Sodium EDTA (37.22 mg/100 ml), D+Trehalose dihydrate (Sigma:T0167)).

For these assays, we measured Glucose, Triglyceride, Glycerol, Trehalose and total protein content in triplicate and we used a visible wavelength spectrophotometer (Epoch: Microplate Spectrophotometer) with absorbance at $544 \mathrm{~nm}, 540 \mathrm{~nm}$ and $750 \mathrm{~nm}$ and 96 well plates, with volumes scaled down from the manufacturer protocols (Ridley et al., 2012).

\section{Active Metabolic Rate Measurement (AMR)}

Flow-through $\mathrm{CO}_{2}$-based respirometry was used to record $V \mathrm{CO}_{2}$, with a similar experimental setup as described by Terblanche et al. (2007). A HiBlow HP40 air pump was used to feed atmospheric air into sodalime (VWR with indicator AnalaR NORMAPUR analytical reagent) and Drierite (W.A. Hammond Drierite Company) scrubber columns, to remove $\mathrm{CO}_{2}$ and water vapour from the air stream, respectively. The flow rate of the airstream was regulated at $80 \mathrm{ml}$ $\min ^{-1}$ by a flow control valve (Model 840, Sierra Side-Trak, Sierra Instruments Inc., Monterey, USA), connected to a mass flow controller (Sable MFC-2). Thereafter, air flowed through the zero channel (cell A) of a calibrated (to 6 ppm $\mathrm{CO}_{2}$ in air) infrared $\mathrm{CO}_{2}-\mathrm{H}_{2} \mathrm{O}$ analyzer (Li-7000, Li-Cor, Lincoln, NE, USA). The airstream then flowed over the test animal in the $5 \mathrm{ml}$ glass 
236 cuvette, which was placed in a programmable water bath (Grant, GP200-R4), programmed using

237 LABWISE software with increasing temperature of $0.25^{\circ} \mathrm{C} \mathrm{min}^{-1}$ (see Basson \& Terblanche,

238 2010). The air leaving the cuvette then entered the analyser through another channel which

239 recorded the difference in $\mathrm{CO}_{2}$ concentration of the air before and after it flowed through the

240 cuvette, at $1 \mathrm{~s}$ intervals. Changes in animal position (activity) were recorded using an infrared

241 activity detector (AD-1, Sable Systems, Las Vegas, NV, USA). Aluminium foil was placed

242 around this cuvette to restrict light exposure and to ensure high quality activity recordings

243 (MacMillan et al., 2012).

244 Four aphids per replicate were weighed to $0.001 \mathrm{mg}$ on an electronic microbalance before and 245 after the experiment and mean mass used as a covariate in statistical analyses. The output from

246 the $\mathrm{CO}_{2}$ analyzer and activity data were recorded with the LiCor 7000 software and analysed

247 using Expedata V1.25 software (Sable Systems International, Las Vegas, NV, USA). Volumes of

$248 \mathrm{CO}_{2}$ in ppm were corrected for baseline drift and then converted to $\mu \mathrm{CO}_{2} \mathrm{~h}^{-1}$ using Expedata

249 software. Rates of $\mathrm{CO}_{2}$ production (in $\mu 1 \mathrm{CO}_{2} \mathrm{~h}^{-1}$ ) were calculated from the whole record by

250 transforming ppm concentration of $\mathrm{CO}_{2}$ to $\mathrm{CO}_{2}$ fraction and then multiplying by the flow rate

$251\left(80 \mathrm{mlmin}^{-1}\right)$. The area under the curve (integral of $\mathrm{mlCO}_{2} \mathrm{~min}^{-1}$ vs min) was calculated. This area

252 was equal to the volume of $\mathrm{CO}_{2}$ produced by each replicate in the cuvette, and this volume was

253 divided by the total period of measurement $(2.30 \mathrm{~h})$, multiplied by 1000 to give $\mu 1 \mathrm{CO}_{2} \mathrm{~h}^{-1}$ to give

254 the metabolic rate per aphid per hour (Castañeda et al., 2009). Metabolic rate was measured for

255 each of the four times two replicate aphids after the final exposure in all experimental groups.

256 Measuring Upper Critical Thermal Limits (CT max $_{\text {max }}$

257 Critical thermal limits were determined by subjecting aphids to a regime of increasing

258 temperatures and monitoring their ability to control their movement: loss of muscular controls to

259 determine their $\mathrm{CT}_{\max }$ threshold. Forty adult aphids were each placed within an individual $5 \mathrm{ml}$

260 plastic tube at a pre-set temperature $\left(25^{\circ} \mathrm{C}\right)$. A programmable water bath was set to increase the

261 temperature from $25^{\circ} \mathrm{C}$ to $35^{\circ} \mathrm{C}$ with a rate of $0.5^{\circ} \mathrm{C} \mathrm{min}-1$ then the temperature was increased to

$26245^{\circ} \mathrm{C}$ with a rate of $0.1^{\circ} \mathrm{C} \mathrm{min}^{-1}$ to minimize the hardening response across a broad range of

263 upper critical temperatures and to determine the temperature at which walking ceased and aphids

264 succumbed (Hazell et al., 2008; Alford et al., 2012b). Upper critical temperature was measured 
265 for 40 adult aphids for each of the three experimental treatments after final heat exposure in all 266 experiments group.

267

268 Statistical Analysis

269 All data were analysed for normality and tested for homogeneity of variances for treatment

270 means using the Levene's Test, in the HOVTEST option of GLM procedure within SAS

271 software (2008). A completely randomized design was employed. One-way analysis of variance

272 was performed using the GLM procedure. Tukey post hoc tests were used to compare means $(\mathrm{P}<$ $2730.05)$.

\section{Results}

\section{Glucose Content}

276 The glucose content of the control group exhibited no significant differences over the course of

277 the experiment (Day 1: $1.61 \pm 0.02$ to Day 3: $1.96 \pm 0.06 \mu \mathrm{g}$ glucose $\mathrm{mg}^{-1}$ (Fig .3A). However, adult

278 aphids in both the prolonged and repeated exposure groups experienced a significant increase in 279 glucose content. After a single cycle of $38^{\circ} \mathrm{C}$ for $1 \mathrm{~h}$ and $25^{\circ} \mathrm{C}$ for $24 \mathrm{~h}$, glucose content increased 280 significantly, nearly one and half fold for aphids in the repeated exposure group $(P<0.0001)$. For 281 the duration of the experiment, the glucose content of aphids in the repeated exposure group 282 peaked at $3.26 \pm 0.02 \mu \mathrm{g}$ glucose $\mathrm{mg}^{-1}$ (Fig. 3A). For adult aphids continuously exposed to $38^{\circ} \mathrm{C}$ 283 for $3 \mathrm{~h}$ (prolonged exposure treatment), glucose content significantly increased compared to the 284 control group $\left(3.01 \pm 0.02 \mu\right.$ g glucose $\left.\mathrm{mg}^{-1}\right)$.

\section{Trehalose content}

286 The trehalose content of aphids exposed to repeated heating events significantly decreased from $2870.44 \pm 0.01$ to $0.27 \pm 0.01 \mu \mathrm{g}$ trehalose $\mathrm{mg}^{-1}$ after the second heating exposure (Fig. 3B). After 288 three cycles of heating, trehalose content of aphids was significantly lower than the control group 289 on the third day of the experiment $(P<0.001)$. For aphids exposed to $38^{\circ} \mathrm{C}$ for $3 \mathrm{~h}$, the trehalose 290 content did not significantly differ $(P=0.329)$ from that of the control group. 
291

292

293

294

295

296

297

298

299

300

301

302

303

304

305

306

307

308

309

310

311

312

313

314

315

316

\section{Protein content}

Similar to glucose and glycerol content, protein content of aphids that were heated during repeated exposures was significantly higher than in the control group and their prolonged exposure counterparts $(P<0.001$; Fig. $3 \mathrm{C})$. After one cycle of $1 \mathrm{~h}$ at $38^{\circ} \mathrm{C}$ and $24 \mathrm{~h}$ at $25^{\circ} \mathrm{C}$, the protein content of aphids was $17.16 \pm 0.06 \mu \mathrm{g}$ protein $\mathrm{mg}^{-1}$, but this value steadily increased every cycle, and by the end of third cycle protein content was $19.79 \pm 0.1 \mu \mathrm{g}$ protein $\mathrm{mg}^{-1}$ (Fig. 3C).

Protein content in aphids heated at $38^{\circ} \mathrm{C}$ for $3 \mathrm{~h}$ did not significantly differ from the control (Fig. 3C).

\section{Glycerol and triglyceride content}

Triglyceride content in aphids did not significantly differ between control and the prolonged exposure groups. However there was a significant drop of triglyceride content in aphids after three cycles of repeated heating in the repeated exposure group: triglyceride content in the repeated exposure group was less than half that of control $(0.659 \pm 0.01)$ and prolonged $(0.597 \pm 0.01)$ aphids and reached $0.324 \pm 0.02 \mu$ g triglyceride $\mathrm{mg}^{-1}(P<0.002$; Fig. 3E).

Glycerol content was significantly higher $(P<0.0001)$ in aphids of the repeated exposure group increasing from $1.53 \pm 0.01$ to $1.96 \pm 0.02 \mu \mathrm{g}$ triglyceride $\mathrm{mg}^{-1}$ after three cycles of heating. There was also significantly higher glycerol content in aphids of the prolonged exposure group compared to the control group $(P=0.0001$; Fig. 3D).

\section{Thermal Tolerance}

There was no significant difference in aphid $\mathrm{CT}_{\max }$ between the thermal treatments (Fig. 4).

\section{Active metabolic rate measurements}

314 There was no significant difference in metabolic rate $24 \mathrm{~h}$ after heating among treatments $(P$ $315=0.6$; Fig. 5A). Aphids from the repeated heating and prolonged heating treatments exhibited significant water loss compared to the control group ( $P=0.04$; Fig. 5b). 


\section{Discussion}

318 In the present study, we examined the physiological consequences of either being exposed to repeat short-period high temperatures bouts with recovery time periods between them, or a single prolonged temperature treatment, in the aphid Myzus persicae (Figure 2). We observed increased physiological costs and benefits during repeated heating exposure: this group of aphids had more glucose and higher expression of proteins and osmolyte compounds such as glycerol compared to the prolonged exposure group. However the repeated high temperature exposure group also had fewer sources of energy such as trehalose and triglyceride compounds compared to the prolonged exposure group. We found that recovery time had more physiological costs (based on production of more protein and consumption of more trehalose and triglyceride) and benefits (based on production of more osmolytes) for repeated high temperature exposure group, but interestingly we saw no changes in thermal tolerance and metabolic rate across treatments.

\section{Impacts of repeated high temperature on thermal tolerance of aphids}

331 Fluctuating temperature studies are better at predicting the thermal tolerance of aphids than constant temperature studies, even when the mean temperatures are the same between constant and fluctuating regimes (Lamb, 1961); constant temperature studies also underestimate critical temperature thresholds as it is known that fluctuating temperatures develop threshold limits (Casagrande and Haynes, 1976; Meats, 1976). The upper critical temperatures in M. persicae start from $38.5^{\circ} \mathrm{C}$ (Broadbent and Hollings, 1951) to $42^{\circ} \mathrm{C}$ (Hazell et al., 2010). To our knowledge just two studies (Davis et al. 2006, Gillespie et al. 2012) have assessed fluctuating high temperatures in M. persicae: but our study is the first to assess physiology of aphids at high temperatures. Davis et al. (2006) examined the effect of high and fluctuating temperatures on the development of $M$. persicae. They demonstrated that under fluctuating temperatures, $M$. persicae had greater fertility and faster development and had the capacity to survive 1 h every day above the $\mathrm{CT}_{\max }$ of $38.5^{\circ} \mathrm{C}$ (Davis et al., 2006). These results are in contrast to Gillespie et al. (2012) who found that under heat wave conditions, the growing population in aphids was lower when exposed to heat waves than weather with periodic hot days. So differences in their results may be due to other factors such as changes in mean temperatures. 
347 Extreme temperature exposure in short bursts often increase survival compared to prolonged

348 exposure. At optimum conditions, injury repair can occur by restoring ion homeostasis (Kostal et 349 al., 2007) and replenishing energy levels. In Drosophila melanogaster, Krebs and Loeschcke 350 (1994) found similar results for effects of heating in adult female flies by exposing them to $36^{\circ} \mathrm{C}$ 351 1-3 times with $48 \mathrm{~h}$ rest between heating exposure. Their results showed that exposure to bouts of 352 stress increased survival temperature to $39^{\circ} \mathrm{C}$.

353 Furthermore, recovery time at optimum temperatures may have permitted aphids to recover from 354 the negative impacts of high temperatures (Hazell et al., 2010). In our study, it appears that 355 recovery times between high temperatures can repair injuries, as aphids exhibited higher levels 356 protein and osmolyte in the repeated exposure treatment compared to the prolonged exposure 357 treatment group: but there was no significant difference in their $\mathrm{CT}_{\max }$ between treatments. One 358 possible explanation is that the proteins and osmolytes were upregulated during the recovery 359 time, but upregulation was not great enough to change their thermal threshold between 360 treatments (Tammariello et al., 1999). One further reason for conservatism of physiological 361 resistance to heat is due to upper thermal tolerance being largely uncorrelated to estimates of 362 natural temperature (Grigg and Buckley, 2013) as a high number of terrestrial organisms are 363 unlikely to evolve physiological resistance to increased heat (Kellermann et al., 2012; Hoffmann 364 et al., 2013). In such cases, development of physiological resistances will be weakened.

365

366

367

368

369

370

371

372

373

374 The osmolyte compounds in aphids heated continuously for $3 \mathrm{~h}$ were less than those aphids 375

\section{Changes in Energy Reserves at Fluctuating Temperatures}

Acclimation impacts the structure of lipid layers (Hazel, 1995), sugar or polyol amount (Hendrix and Salvucci, 1998) and metabolic rate (Hoffmann and Parsons, 1997): all of which can influence temperature resistance (Andersen et al., 2010). Whiteflies and aphids appear to be the first reported organisms that collected polyols in response to high temperatures (Hendrix and Salvucci, 1998). Sugars and polyols balance out and stabilize the natural structure of proteins, protecting them from warm denaturation (Back et al., 1979).

\footnotetext{
exposed to three $1 \mathrm{~h}$ cycles of repeated high temperatures. Adaptations to surviving high
} 
376 temperatures, such as stress protein production and the synthesis of resources like glucose and

377 trehalose (Hottiger et al., 1994; Jain and Roy, 2009). Accordingly, we anticipated that repeated

378 high temperatures would result in the consumption of vital energy reserves.

379

380 Our results indicate that repeated high temperature exposure is physiologically costly for aphids

381

382

383

384

385

386

387

388

389

390

391

392

393

394

395

396

397

398

399

400

401

402

403

404 compared to prolonged high temperature exposure, as there is a significantly lower amount of trehalose and triglyceride production after repeated high temperatures. Trehalose and proteins play important roles in stress responses (Parsell and Lindquist, 1993; Feder and Hofmann, 1999; Salvucci et al., 2000; Jain and Roy, 2009; Smith et al., 2012). Induction of thermal tolerance by trehalose is also inferred from the fact that the level of trehalose is correlated with thermal tolerance (Hottiger et al., 1994): with this in mind we measured the content of these two known compounds in M. persicae. Protein content was higher in aphids of the repeated high temperature treatment group, which has a well-defined role as a protective material at high temperatures (Jain and Roy, 2009) and this result is in agreement with previous studies (Huang et al., 2007; Tollarová-Borovanská et al., 2009; Zhang et al., 2011). We hypothesise that in repeated high temperature exposure, protein production is triggered once the aphids are returned to their recovery temperature: a trigger that is not available to aphids exposed to prolonged periods of high temperature.

An unusual result in our study was that the amount of trehalose decreased in aphids exposed to repeated high temperatures compared to the aphids exposed to prolonged high temperatures. This contradicts the findings of previous studies assessing trehalose after exposure to high temperatures (Hottiger et al., 1994; Jain and Roy, 2009) but does support the findings of Teets et al., (2010). Trehalose may be used to produce an osmolyte, such as mannitol, in aphids which is important at high temperatures (Hendrix and Salvucci, 1998). Trehalose can also function as a reserve carbohydrate in others, which acts as a protectant. For example it has been noted that trehalose accumulates under conditions of environmental stress, such as desiccation and is rapidly metabolized in rehydration. A reserve function could be inferred. Trehalose can also accumulate in response to other stresses, such as heat or osmotic shock (Newman et al., 1993), 
405 for example Lalouette et al. (2007) demonstrated that trehalose can be changed to glycogen

406 therefore is related to energy storage functions.

407

408

409

Triacylglycerols constitute a large part of the aphid lipid assemblage (Itoyama et al. 2000) and serve as a reservoir for fatty acids that can be used for energy production. Very large amounts of

410 triacylglycerol can occur in aphids, comprising 20-30\% of fresh body weight (Strong, 1963;

411

Sutherland, 1968). According to expectations, we observed lower amount of triglyceride content after repeated high temperatures compared to the prolonged treatment aphids. One explanation is, these storage lipids are used as a source of metabolite energy for physiological processes: many insects use lipids as an energy source, and fatty acids are stored in the fat body in the form of triacylglycerol (Blacklock and Ryan, 1994; Itoyama et al., 2000). Since glycerol is known to maintain cells from hyperthermic cell death, induced thermal protection and warming protection may be applied by adjustment of either protein or membranes (Henle and Warters, 1982). Our results demonstrated that glycerol in aphids exposed to repeated extreme heat exposure (by the end of the third cycle) is higher than the levels in aphids exposed to prolonged thermal extremes; and this is in accordance with the role of this compound during heat stress (Benoit et al., 2007).

Aphids are very sensitive to acute changes in temperature rather than the duration of stress (Davis et al., 2006). We found significant changes in metabolite reserves after repeated high temperature exposure compared to the prolonged temperature exposure treatments with the same duration indicating that the number of extreme high temperature events is more important than the duration of extreme temperatures although the $\mathrm{CT}_{\max }$ of aphids was constant for both temperature regimes.

\section{Impacts of repeated high temperature on metabolic rate of aphids}

430 Respiration is the first process restricted in animals at low and high temperatures, and is connected to the limitation of blood circulation and ventilation (Portner, 2001). We observed no significant differences in metabolic rate $24 \mathrm{~h}$ after heating and this is in contrast to previous

433 studies looking at metabolic rates at upper critical temperature (Klok et al., 2004; Boardman et al., 2013). Elevated standard metabolic rate after stressful conditions is a repair cost (Boardman et al., 2013). We measured active metabolic rate with increasing temperatures not resting 
436 metabolic rate or standard metabolic rate at $25^{\circ} \mathrm{C}$. In addition, we also found that there was a

437 lower rate of water loss after heating: this may be due to aphids closing their spiracles to reduce

438 water loss after heating events, and possibly a strategy for heat resistance.

\section{Perspectives}

440 To date, the key assessment of environmental stress tolerance in the aphid, M. persicae has been

441 at low temperatures and in most known studies; the aphids have been exposed to a single stress

442 event. In natural conditions, M. persicae is exposed to repeated bouts of high temperature

443 punctuated by periods of recovery. Furthermore, because aphids are known to respond

444 differently to consistent versus more 'normal' fluctuating temperatures, conclusions drawn from

445 constant temperature studies may be unreliable. We suggest future experiments incorporate a

446 repeated stress and recovery pattern into their methodologies to fully assess responses to extreme

447 temperature exposure to reflect the natural growing conditions of this species of aphid and also,

448 incorporate biological and fitness studies to physiological studies at the same time to reach

449 comprehensive achievements in this filed.

450 Acknowledgements. We thank Emma Ridley for her suggestions in my nutritional assays, Ary

451 Anthony Hoffmann, John Terblanche, Jesper Givskov Sørensen, Katie Marshall and Leigh

452 Boardman for their suggestions in experimental design development and Berlizé Groenewald for

453 assistance with respirometry setup and calculations and Hamid Reza Hemati Matin for his

454 assistance in analysing data. We thank Bianca Boss-Bishop and Sarah Hill for commenting on

455 previous version of the manuscript and Leigh Boardman and two anonymous referees for

456 suggestions that led to an improved manuscript.

457 Supplemental Information: https://figshare.com/s/407bb6e98a7c05c3ac3f

458

459

460

461

462

463 


\section{References}

476

477

478

479

480

481

482

483

484

485

486

487

488

489

490

491

492

493

494

495

496

497

498

499
Alford, L., Blackburn,T. M. and Bale, J. S.2012a. Effect of latitude and acclimation on the lethal temperatures of the peach-potato aphid Myzus persicae.Agricultural and forest entomology. 14:69-79.

Alford, L., Blackburn, T. M. and Bale, J. S. 2012b. Effects of acclimation and latitude on the activity thresholds of the aphid Myzus persicae in Europe. Journal of Applied Entomology. 136:332-346.

Andersen, L. H., Kristensen, T. N., Loeschcke, V., Toft, S. and Mayntz, D. 2010. Protein and carbohydrate composition of larval food affects tolerance to thermal stress and desiccation in adult Drosophila melanogaster. Journal of Insect Physiology. 56:336-340.

Andrew, N. R. 2013. Population dynamics of insects: impacts of a changing climate. In: The Balance of Nature and Human Impact. (ed Rohde K). Cambridge University Press.311323.

Angilletta, M. J. 2009. Thermal adaptation: a theoretical and empirical synthesis. Oxford, UK: Oxford University Press.

Back, J. F., Oakenfull, D. and Smith, M. B.1979. Increased thermal stability of proteins in the presence of sugars and polyols. Biochemistry. 18:5191-5196.

Bale, J. S., Harrington, R. and Clough, M. S.1988. Low temperature mortality of the peachpotato aphid Myzus persicae. Ecological Entomology. 13:121-129.

Basson, C. H. and Terblanche, J. S.2010. Metabolic responses of Glossina pallidipes (Diptera: Glossinidae) puparia exposed to oxygen and temperature variation: implications for population dynamics and subterranean life. Journal of Insect Physiology .56:1789-1797.

Bauerfeind, S. S. and Fischer, K..2014. Simulating climate change: Temperature extremes but not means diminish performance in a widespread butterfly. Population Ecology. 56:239250 . 
500

501

502

503

504

505

506

507

508

509

510

511

512

513

514

515

516

517

518

519

520

521

522

523

524

525

526

527

528

529

530

531

532

533

534

535

536

537

538

539

540

541

542

543

544

Beardmore, J. A. and Levine, L. 1963. Fitness and environmental variation. I. A study of some polymorphic populations of Drosophila pseudoobscura. Evolution. 17:121-129.

Benoit, J. B., Lopez-Martinez, G., Michaud, M. R., Elnitsky, M. A., Lee, R. E. and Denlinger, D. L.2007. Mechanisms to reduce dehydration stress in larvae of the Antarctic midge, Belgica antarctica. Journal of Insec physiology. 53:656-667.

Bezemer, T. M., Jones, T. H. and Knight, K. J.1998. Long-term effects of elevated CO2 and temperature on populations of the peach potato aphid Myzus persicae and its parasitoid Aphidius matricariae. Oecologia. 116:128 -135.

Blacklock, B. J. and Ryan, R. O.1994. Hemolymph lipid transport. Insect Biochem. Molcular Biology 24:855-873.

Blackman, R. L. and Eastop, V. F.1984. Aphids on the worlds crops, an identifcation guide. Wiley, New York.

Blackman, R. L. and Eastop, V. F. 2000. Aphids on the world's crops: An identification and information guide. John Wiley \& Sons Ltd., Chichester.

Boardman, L., Sorensen, J. G. and Terblanche, J. S.2013. Physiological responses to fluctuating thermal and hydration regimes in the chill susceptible insect, Thaumatotibia leucotreta. .Journal of Insect Physiology. 59:781-794.

Broadbent, L. and Hollings, M. 1951. The influence of heat on some aphids. Annual Applied Biology. 38.

Casagrande, R. A. and Haynes, D. L.1976. A predictive model for cereal leaf beetle mortality from sub-freezing temperatures. Environmental Entomology.5:761-769.

Castañeda, L. E., Figueroa, C. C., Fuentes-Contreras, E., Niemeyer, H. M. and Nespolo, R. F.2009. Energetic costs of detoxification systems in herbivores feeding on chemically defended host plants: a correlational study in the grain aphid, Sitobion avenae. Journal of Experimental Biology. 212:1185-1190.

Chown, S. L., Hoffmann, A. A., Kristensen, T. N., Angilletta, M. J., Stenseth, N. C. and Pertoldi, C.2010. Adapting to climate change: a perspective from evolutionary physiology. Climate Research. 43:3-15.

Chown, S. L., Sorensen, J. G. and Terblanche, J. S.2011. Water loss in insects: an environmental change perspective. J. Insect.Physiol. 57:1070-1084.

Clark, M. S. and Worland, M. R.2008. How insects survive the cold: molecular mechanisms-a review. Journal of Comperative Physiology. B. 178:917-933.

Cloudsley-Thompson, J. L.1953. The significance of fluctuating temperatures on the physiology and ecology of insects. Entomologist. 86:183-189.

Clough, M. S., Bale, J. S. and Harrington, R.1990. Differential cold hardiness in adults and nymphs of the peach-potato aphid Myzus persicae. Annual Applied Biology. 116:1-9.

Colinet, H., B. J. Sinclair, P. Vernon, and D. Renault. 2015. Insects in Fluctuating Thermal Environments. Annual Review of Entomology 60:7.1-7.18.

CSIRO-ABM.2014. State of the Climate 2014. CSIRO and the Australian Bureau of Meteorology, Canberra.

Davis, J. A., Radcliffe, E. B. and Ragsdale, D. W. 2006. Effects of high and fluctuating temperatures on Myzus persicae (Hemiptera: Aphididae). Environmental Entomology. 35:1461-1468. 
545

Dawson, T. P., Jackson, S. T., House, J. I., Prentice, I. C. and Mace, G. M. 2011. Beyond predictions: biodiversity conservation in a changing climate. Sci. Total .Environ. 332:5358.

Dixon, A. F. G. (2005). Insect herbivore-host dynamics: Tree-dwelling aphids. Cambridge,UK: Cambridge University Press.

Douglas, A. E.1988. On the source of sterols in the green peach aphid, Myzus persicae, reared on holodicdiets. Journal of Insec Physiology.34:403-408.

Feder, M. E. and Hofmann, G. E. 1999. Heat shock proteins, molecular chaperones, an dthe stress response: evolutionary and ecologicaly physiology. The Annual Review of Plavt Biology. 61:243-282.

Fischer, K., N. Kölzow, H. Höltje, and I. Karl. 2011. Assay conditions in laboratory experiments: is the use of constant rather than fluctuating temperatures justified when investigating temperature-induced plasticity? Oecologia 166:23-33.

Gia, M. H. and N. R. Andrew.2015. Performance of the cabbage aphid Brevicoryne brassicae (Hemiptera: Aphididae) on canola varieties. General and Applied Entomology.43:1-10.

Gillespie, D. R., Nasreen, A., Moffat, C. E., Clarke, P. and Roitber, B. D. 2012. Effects of simulated heat waves on an experimental community of pepper plants, green peach aphids and two parasitoid species. Oikos .121:149-159.

Grigg, J. W. and Buckley, L. B.2013. Conservatism of lizard thermal tolerances and body temperatures across evolutionary history and geography. Biology Letters.9:20121056.

Gu, H., Fitt, G. P. and Baker, G. H.2007. invertebrate pests of canola and their managemant in Australia: a review. Australian Journal of Entomology. 46:231-243.

Hazel, J. R.1995. Thermal adaptation in biological membranes: is homeoviscous adaptation the explanation? Annu. Rev. Physiol .57:19-42.

Hazell, S. P., Neve, B. P., Groutides, C., Douglas, A. E., Blackburn, T. M. and Bale, J. S. 2010. Hyperthermic aphids: insights into behaviour and mortality. Journal of Insect Physiology.56:123-131.

Hazell, S. P., Pedersn, B. P., Worland, M. R., Blackburn, T. M. and Bale, J. S.2008. A method for the rapid measurment of thermal tolerance in studies of small insects. Physiological Entomology. 33:389-394.

Hendrix, D. L. and Salvucci, M. E.1998. Polyol metabolism in homopterans at high temperature: accumulation of mannitol in aphids (Aphididae: Homoptera) and sorbitol in whiteflies (Aleyrodidae: Homoptera). Comperative Biochemistry and Physiology of Zoology.120:487-494.

Henle, K. J., Peck, W. J. and Higashikubo, R.1983. Protection against Heat-induced cell killing by polyols in vitro. Cancer. Res. 43:1624-1627.

Henle, K. J. and Warters, R. L.1982. Heat protection by glycerol in vitro. Cancer Research. 42:2171-2176.

Hoffmann, A. A., Chown, S. L., Clusella-Trullas, S. and Fox, C.2013. Upper thermal limits in terrestrial ectotherms: how constrained are they? Functional Ecology .27:934-949.

Hoffmann, A. A. and Parsons, P. A.1997. Extreme Environmental Change and Evolution. Cambridge, UK: Cambridge University Press.

Hottiger, T., de Virgilio, C., Hall, M. N., Boller, T. and Wiemken, A.1994. The role of trehalose synthesis for the acquisition of thermotolerance in yeast. II. Physiological concentrations 
590

591

592

593

594

595

596

597

598

599

600

601

602

603

604

605

606

607

608

609

610

611

612

613

614

615

616

617

618

619

620

621

622

623

624

625

626

627

628

629

630

631

632

633

634 of trehalose increase the thermal stability of proteins in vitro. Eurpean Journal of Biochemistry .219:187-193.

Howling, G. G., Bale, J. S. and Harrington, R. 1994. Effects of extended and repeated exposures to low temperature on mortality of the peach-potato aphid Myzus persicae. Ecological Entomology .19:361 -366.

Huang, L. H., Chen, B. and Kang, L. 2007. Impact of mild temperature hardening on thermotolerance, fecundity, and Hsp gene expression in Liriomyza huidobrensis. Journal of Insect Physioogyl.53:1199-1205.

Huey, R. B.(1991). Physiological consequences of habitat selection. Am. Nat 137:S91- S115.

Huey, R. B., Kearney, M. R., Krockenberger, A., Holtum, J. A., Jess, M. and Williams, S. E.2012. Predicting organismal vulnerability to climate warming: roles of behaviour, physiology and adaptation. Philosophy Transactions. Research Society B: Biology .367:1665-1679.

IPCC, 2014.2014: Synthesis Report. Contribution of Working Groups I, II and III to the Fifth Assessment Report of the Intergovernmental Panel on Climate Change [Core Writing Team, R.K. Pachauri and L.A. Meyer (eds.)]. IPCC, Geneva, Switzerland, 151 pp.

Itoyama, K., Tojo, S., Yanagita, T. and Hardie, J.2000. Lipid composition in long-day and shortday forms of the black bean aphid, Aphis fabae. Journal of Insect Physiology .46:119125.

Jain, N. K. and Roy, I. 2009. Effect of trehalose on protein structure. Protein. Sci. 18:24-36.

Ju, R. T., Gao, L., Zhou, X. H. and Li, B.2013. Tolerance to high temperature extremes in an invasive lace bug, Corythucha ciliata (Hemiptera: Tingidae), in subtropical china. PLoS ONE. 8:e54372.

Kellermann, V., Overgaard, J., Hoffmann, A. A., Fløjgaard, C., Svenning, J.C. and Loeschcke, V.2012. Upper thermal limits of Drosophila are linked to species distributions and strongly constrained phylogenetically. Proceedings of the National Academy of Sciences. US A.

Kim, D. and Lee, Y. J.1993. Effect of glycerol on protein aggregation: quantitation of thermal aggregation of proteins from CHO cells and analysis of aggregated proteins. Journal of Thermal Biology .18:41-48.

Klok, J. C., Sinclair, B. J. and Chown, S. L.2004. Upper thermal tolerance and oxygen limitation in terrestrial arthropods. Journal of Experimental Biology. 207:2361-2370.

Kostal, V., Renault, D., Mehrabianová, A. and Bastl, J.2007. Insect cold tolerance and repair of chill-injury at fluctuating thermal regimes: Role of ion homeostasis. Comperative Biochemistry and Physioogyl. 147: 231-238.

Krebs, R. A. and Loeschcke, V.1994. Effects of exposure to short-term heat stress on fitness components in Drosophila melanogaster. Journal of Evoloution Biology. 7:39-49.

Lalouette, L., Kostal, V., Colinet, H., Gagneul, D. and Renault, D.2007. Cold exposure and associated metabolic changes in adult tropical beetles exposed to fluctuating thermal regimes. FEBS J.274:1759-1767.

Lalouette, L., Williams, C. M., Hervant, F., Sinclair, B. J. and Renault, D.2011. Metabolic rate and oxidative stress in insects exposed to low temperature thermal fluctuations. Comperative Biochemistry Physiology A. 158:229-234.

Lamb, K. P.1961. Some effects of fluctuating temperatures on metabolism, development, and rate of population growth in the cabbage aphid, Brevicoryne Brassica. Ecology .42:740745. 
635

636

637

638

639

640

641

642

643

644

645

646

647

648

649

650

651

652

653

654

655

656

657

658

659

660

661

662

663

664

665

666

667

668

669

670

671

672

673

674

675

676

677

678
Lean, J. L. and Rind, D. H.2008. How natural and anthropogenic influences alter global and regional surface temperatures: 1889 to 2006. Geophysical Research Letters. 35:1-6.

Lin, P. S., Hefter, K. and Ho, K. C.1984. Modification of membrane function, protein synthesis, and heat killing effect. Cancer Research. 44:5776-5784.

MacMillan, H. A., Williams, C. M., Staples, J. F. and Sinclair, B. J. 2012. Metabolism and energy supply below the critical thermal minimum of a chillsusceptible insect. Journal of Experimental Biology .215:1366-1372.

Marshall, K. E. and B. J. Sinclair. 2011. The sub-lethal effects of repeated freezing in the woolly bear caterpillar Pyrrharctia isabella. The Journal of Experimental Biology , 214:12051212.

Meats, A. 1976. Developmental and long-term acclimation to cold by the Queensland fruit-fly (Dacus tryoni) at constant and fluctuating temperatures. Journal of Insec physiology. 22:1013-1019.

Meng, F. G., Hong, Y. K., He, H. W., Lyubarev, A. E., Kurganov, B. I., Yan, Y. B. and Zhou, H. M..2004. Osmophobic effect of glycerol on irreversible thermal denaturation of rabbit creatine kinase. Biophyicss Journal. 87:2247-2254.

Mironidis, G. K. and Savopoulou-Soultani, M. 2010. Effect of heat shock on survival and reproduction of Helicoverpa armigera (Lepidoptera: Noctuidae) adults. Journal of Thermal Biology. 35:59-69.

Newman, Y. M., Ring, S. G. and Colaco, C.1993. The role of trehalose and other carbohydrates in biopreservation. Biotechnology \& Genetic Engineering Reviews. 11:263-294.

Niehaus, A. C., Angilletta, M. J., Jr., Sears, M. W., Franklin, C. E. and Wilson, R. S. 2012. Predicting the physiological performance of ectotherms in fluctuating thermal environments. Journal of Experimental Biology. 215:694-701.

O'doherty, R. and Bale, J. S.1985. Factors affecting the cold hardiness of the peach-potato aphid Myzus persicae. Annual Applied Biology. 106:219-228.

Parsell, D. A. and Lindquist, S.1993. The function of heat shock proteins in stress tolerance: Degradation and reactivation of dameged proteins. Annual Review of Genetics. 27:437496.

Portner, H. O.2001. Climate change and temperature-dependent biogeography: oxygen limitation of thermal tolerance in animals. Naturwissenschaften. 88:137-146.

Pörtner, H. O., Bennett, A. F., Bozinovic, F., Clarke, A., Lardies, M. A. and Lenski, R. E. et al.2006. Trade-offs in thermal adaptation: in need of a molecular to ecological integration. Physiological and Biochemical Zoology . 79:295-313.

Rahmstorf, S. and Coumou, D. 2011. Increase of extreme events in a warming world.Proceedings of the National Academy of Sciences.108:17905-17909.

Ridley, E., Wong, A. C.-N., Westmiller, S. and Douglas, A. E.2012. Impact of the resident microbiota on the nutritional phenotype of Derosophila melanogaster. PLoS ONE. 7:e36765.

Salvucci, M. E., Stecher, D. S. and Henneberry, T. J.2000. Heat shock proteins in whiteflies, an insect that accumulates sorbitol in response to heat stress. Journal of Thermal Biology. 25:363-371. 
679

680

681

682

683

684

685

686

687

688

689

690

691

692

693

694

695

696

697

698

699

700

701

702

703

704

705

706

707

708

709

710

711

712

713

714

715

716

717

718

719

720

721

722

723
Schimpf, N. G., Matthews, P. G., Wilson, R. S. and White, C. R.2009. Cockroaches breathe discontinuously to reduce respiratory water loss. Journal of Experimental Biology .212:2773-2780.

Sinclair, B. J., Terblanche, J. S., Scott, M. B., Blatch, G. L., Klok, C. J. and Chown, S. L.2006. Environmental physiology of three species of Collembola at CapeHallett, North Victoria Land, Antarctica. Journal of Insec physiology. 52:29-50.

Smith, H. A., Burns, A. R., Shearer, T. L. and Snell, T. W.2012. Three heat shock proteins are essential for rotifer thermotolerance. Journal of Experimental Marine Biology and Ecology . 413:1-6.

Somero, G. N.2010. The physiology of climate change: how potentials for acclimatization and genetic adaptation will determine 'winners' and 'losers'. Journal of Experimental Biology.213:912-920.

Storey, K. B. and Storey, J. M. 2004. Metabolic rate depression in animals: transcriptional and translational controls. Biological Reviews.79:207-233.

Strong, F. E. (1963). Studies on lipids in some homopterous insects. Hilgardia .34:43-61.

Sutherland, O. R. W.1968. Dormancy and lipid storage in the pemphigine aphid Thecabious affinis. Entomologia Experimentalis et Applicata. 11:348-354.

Tammariello, S. P., Rinehart, J. P. and Denlinger, D. L.1999. Desiccation elicits heat shock protein transcription in the flesh fly, Sarcophaga crassipalpis, but does not enhance tolerance to high or low temperatures. Journal of Insect Physiology .45:933-938.

Teets, N. M., Kawarasaki, Y., Lee, R. E., Jr. and Denlinger, D. L.2010. Survival and energetic costs of repeated cold exposure in the Antarctic midge, Belgica abtarctica: a comparison between frozen and supercooled larvae. Journal of Experimental Biology .214:806-814.

Terblanche, J. and Chown, S. 2007. The effects of temperature, body mass and feeding on metabolic rate in the tsetse fly Glossina morsitans centralis. Physiological Entomology. 32:175-180.

Tollarová-Borovanská, M., Lalouette, L. and Koštál, V.2009. Insect cold tolerance and repair of chill-injury at fluctating thermal regimes: Role of $70 \mathrm{kDa}$ heat shock protein experssion. CryoLetters. 30:312-319.

Vasseur, D. A., DeLong, J. P., Gilbert, B., Greig, H. S., Harley, C. D., McCann, K. S., Savage, V., Tunney T. D. and O'Connor, M. I.2014. Increased temperature variation poses a greater risk to species than climate warming. Proceeding Biology Society.281:20132612.

Vorburger, C.2004. Cold tolerance in obligate and cyclical parthenogens of the peach-potato aphid, Myzus persicae. Ecological Entomology. 29:-505.

Wang, H.S., Zhou, C.S., Gho, W. and Kang, L.2006. Thermoperiodic acclimations enhance cold hardiness of the eggs of the migratory locust. Cryobiology. 53:206-217.

Yocum, G. D., Greenlee, K. J., Rinehart, J. P., Bennett, M. M. and Kemp, W. P. 2011. Cyclic $\mathrm{CO} 2$ emissions during the high temperature pulse of fluctuating thermal regime in eyepigmented pupae of Megachile rotundata. Comparative Biochemistry and PhysiologyA $.160: 480-485$.

Zhang, J., Marshall, K. E., Westwood, J. T., Clark, M. S. and Sinclair, B. J.2011. Divergent transcriptomic responses to repeated and single cold exposures in Drosophila melanogaster. Journal of Experimental Biology .214:4021-4029. 
724 Zhao, F., W. Zhang, A. A. Hoffmann, and C. S. Ma. 2014. Night warming on hot days produces

725

726

727

728

729

730

731

732

733

734

735

736

737

738

739

740

741

742

743

744

745

746

747

748

749 novel impacts on development, survival and reproduction in a small arthropod. Journal of Animal Ecology 83:769-778. 
750 Figure Captions:

751 Fig 1. Diet cages were constructed from rigid clear PVC plastic tubes, $12 \mathrm{~cm}$ in diameter (aphid

752 feeding) and covered with a $7 \times 7 \mathrm{~cm}$ sheet of Parafilm laboratory film.

753 Fig 2. Experimental design, all experiments were performed on adult aphids, that were 6 days old 754 on the first experimental day. Each black rectangle represents a $1 \mathrm{~h}$ exposure to $38^{\circ} \mathrm{C}$. The blue 755 rectangle represents a $3 \mathrm{~h}$ exposure to $38^{\circ} \mathrm{C}$. Adults were kept at $25^{\circ} \mathrm{C}$ as the control group 756 (yellow line). Red dots indicate sampling points. All samples were collected $24 \mathrm{~h}$ after final 757 treatments.

758 Fig 3. Mean ( \pm s.e) (A) Glucose, (B) Trehalose, (C) Protein, (D) glycerol and (E) Triglyceride 759 content of Myzus persicae during repeated (R1, R2, R3), prolonged (P) and control state (C1, C2, 760 C3). The metabolite content is based on the mean of four replicates, two aphids per replicate for 761 the all metabolites. Post-hoc pairwise differences among treatments indicated by stars.

Fig 4. Mean ( \pm s.e) thermal tolerance point $\left(\mathrm{CT}_{\max }\right)$ of aphids among control $(\mathrm{C})$, prolonged $(\mathrm{P})$

764

765

766

767

768

769

770

771

772

773

774

775

776

777

778 and repeated $(R)$ exposure treatments.

Fig 5. Mean ( \pm s.e) (A) $\mathrm{CO}_{2}$ production $\left(\mu 1 \mathrm{CO}_{2} \mathrm{~h}^{-1}\right.$ ) and (B) $\mathrm{H}_{2} \mathrm{O}$ output rates $\left(\mu \mathrm{g} \mathrm{H}_{2} \mathrm{O}^{-1}\right)$ of aphids among control $(\mathrm{C})$, prolonged $(\mathrm{P})$ and repeated $(\mathrm{R})$ exposure treatments. Metabolic rate based on four times two replicate. Post-hoc pairwise differences among treatments indicated by stars.

Table captions

Table 1. Concentrations and composition of the artificial diet used to rear Myzus persicae. Molecular weight (MW); molar Mass (mM) and mole percent (Mol\%).

Table 2. Energy reserves, osmolytes concentration and protein mass of Myzus persicae in three treatment groups: maintained at $25^{\circ} \mathrm{C}$ (control), heated for a single bout of $3 \mathrm{~h}$ at $38^{\circ} \mathrm{C}(1 \times 3 \mathrm{~h})$ and heated for three bouts of $1 \mathrm{~h}$ at $38^{\circ} \mathrm{C}\left(3^{\mathrm{x}} 1 \mathrm{~h}\right)$. Significant values in bold. 
Figure 1

782

783

784

785

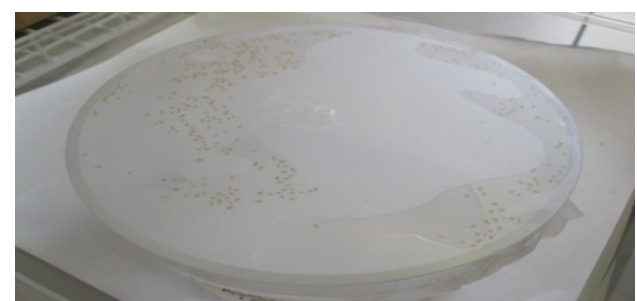

786

787

788

789

Figure 2 - call treatments: prolonged exposure and repeated exposure, heating was set at 7900.5 degrees C. min $^{-1}$.

791

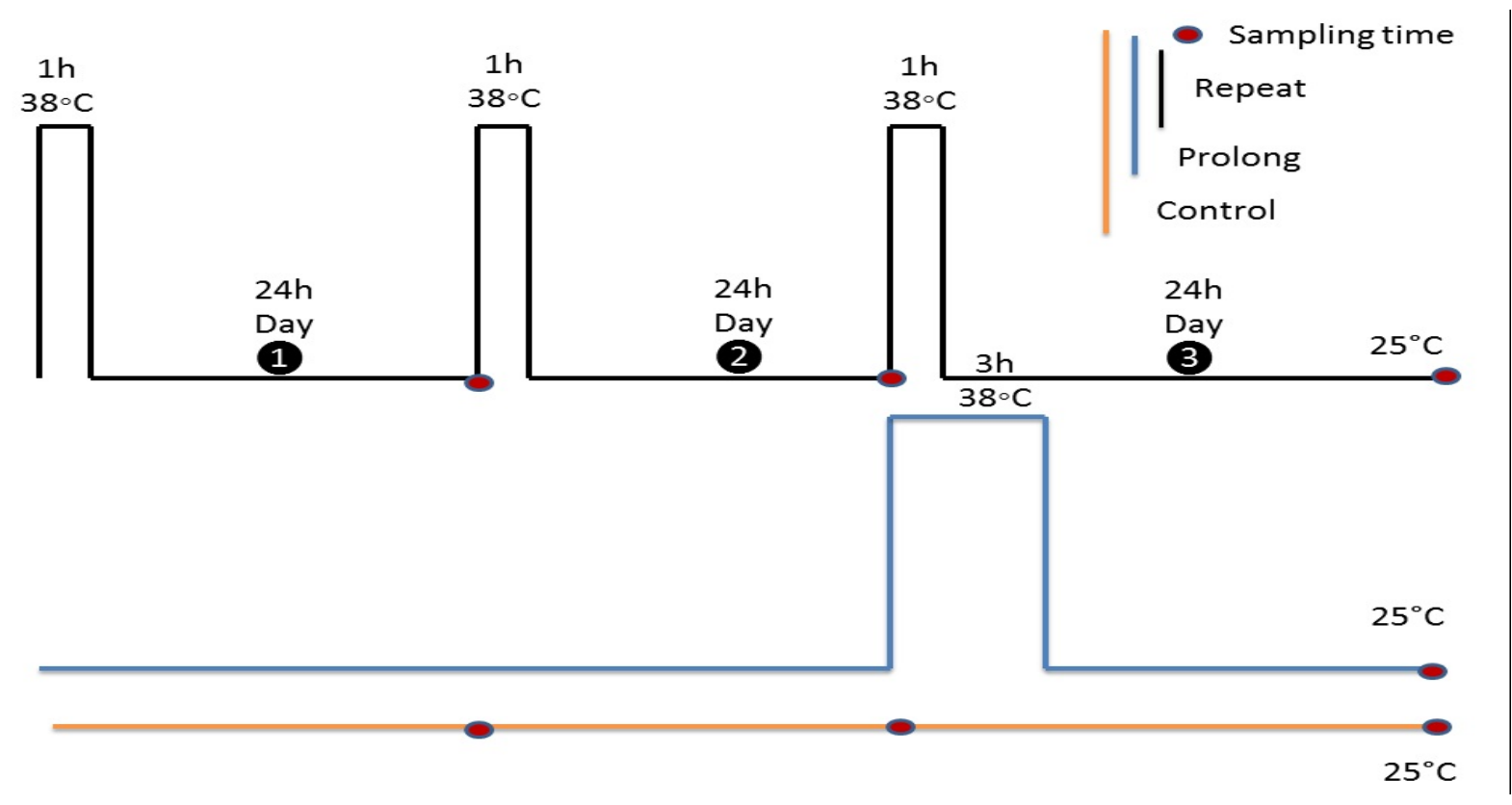

792

793

794 

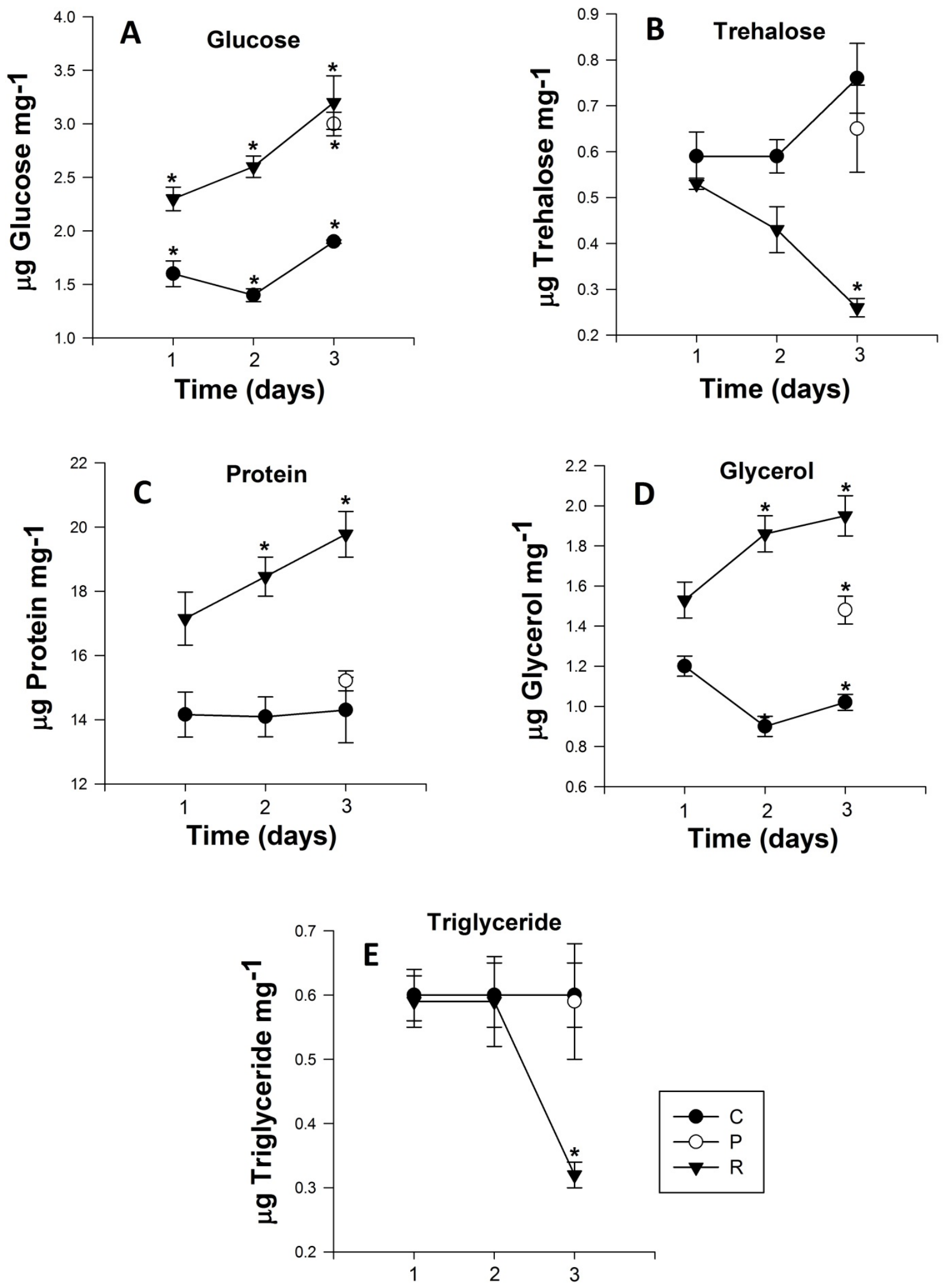

Time (days) 
$800 \quad$ Figure 4

801

802

803

804

805

806

807

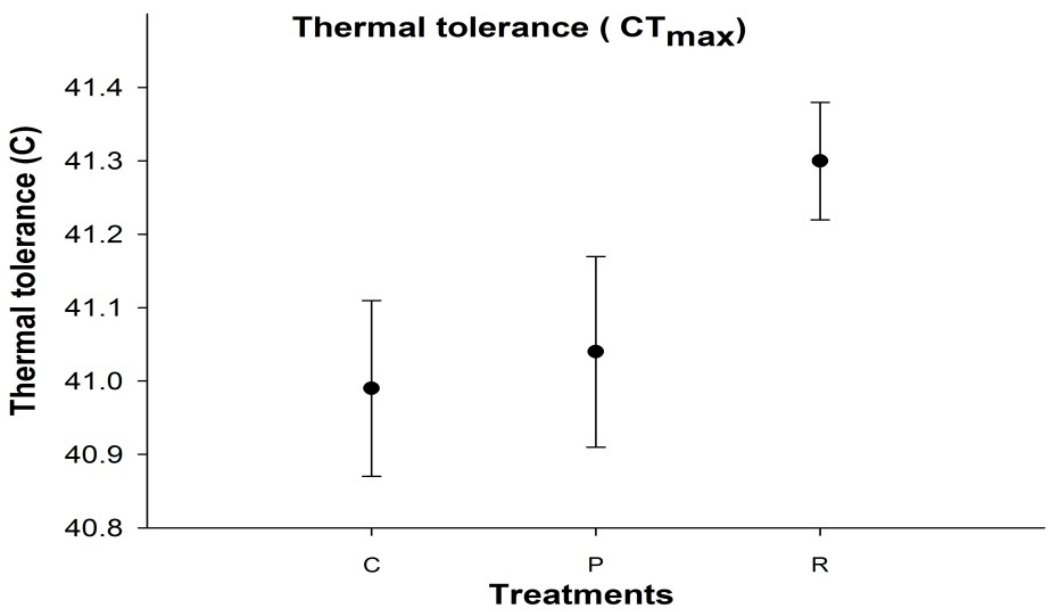

808

809

810

811 Figure 5
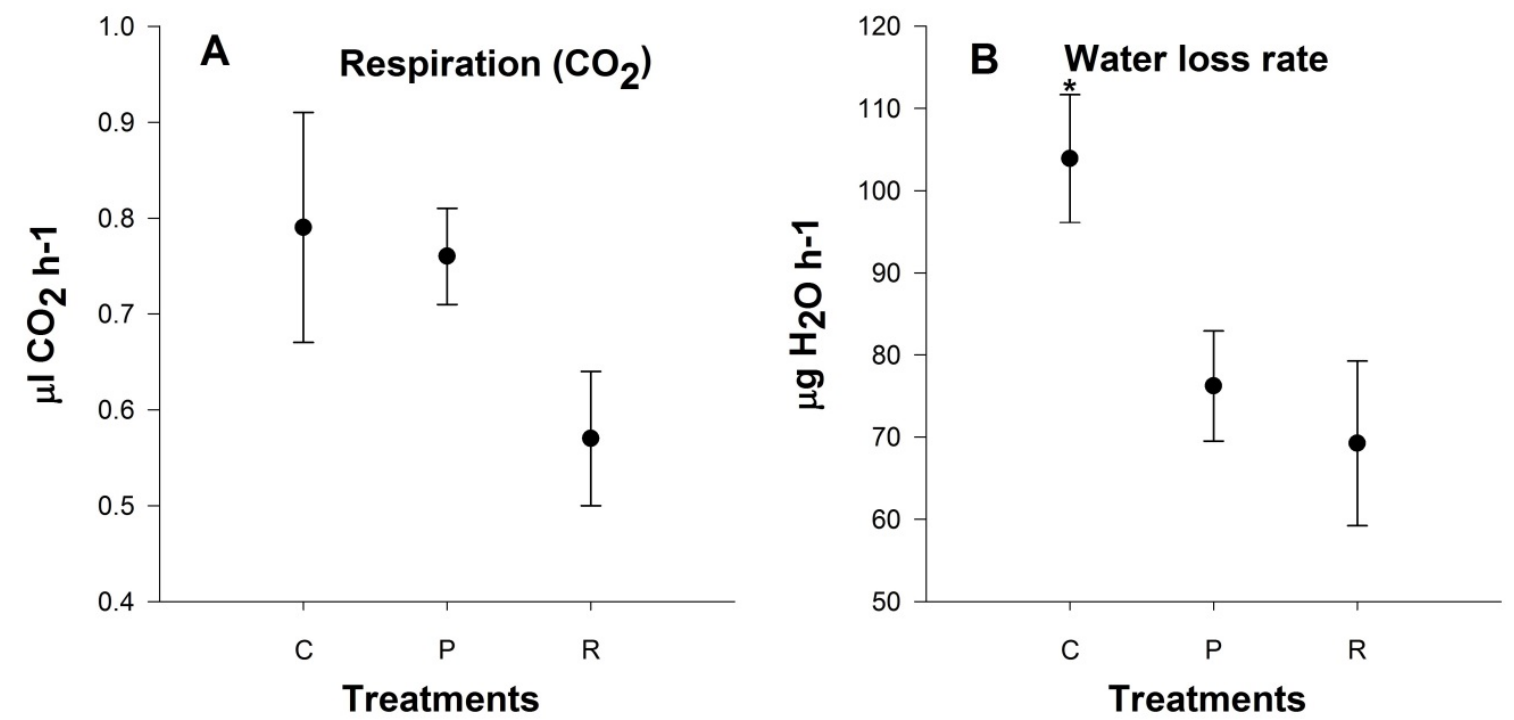

812

813

814 
816 Table 1

817

\begin{tabular}{|c|c|c|c|c|c|}
\hline Amino Acid & MW & Mol\% & $150 \mathrm{mM}$ & Sucrose mix & $\begin{array}{l}1000 \\
\mathrm{mM}\end{array}$ \\
\hline Alanine & 89.09 & 3.8 & $50.8 \mathrm{mg}$ & ascorbic acid & $10 \mathrm{mg}$ \\
\hline Asparagine & 150.1 & 9.5 & $213.9 \mathrm{mg}$ & citric acid & $1 \mathrm{mg}$ \\
\hline $\begin{array}{l}\text { Aspartate/Aspartic } \\
\text { Acid }\end{array}$ & 133.1 & 9.5 & $189.7 \mathrm{mg}$ & $\mathrm{MgSO}_{4}$ & $11 \mathrm{mg}$ \\
\hline Cysteine & 157.6 & 1.8 & $42.5 \mathrm{mg}$ & sucrose & $3400 \mathrm{mg}$ \\
\hline Glutamic Acid & 147.13 & 5.6 & $123.6 \mathrm{mg}$ & Mineral stock & \\
\hline Glutamine & 146.1 & 11 & $241.1 \mathrm{mg}$ & $\mathrm{FeCl}_{3}$ & $13.1 \mathrm{mg}$ \\
\hline Glycine & 75.07 & 0.8 & $9.0 \mathrm{mg}$ & $\mathrm{CuCl}_{2} \cdot 2 \mathrm{H}_{2} \mathrm{O}$ & $1.7 \mathrm{mg}$ \\
\hline Proline & 115.1 & 3.8 & $65.6 \mathrm{mg}$ & $\mathrm{MnCl}_{2} \cdot 4 \mathrm{H}_{2} \mathrm{O}$ & $4 \mathrm{mg}$ \\
\hline Serine & 105.09 & 3.8 & $59.9 \mathrm{mg}$ & $\mathrm{ZnCl}_{2}$ & $13.6 \mathrm{mg}$ \\
\hline Tyrosine & 181.2 & 0.4 & $10.9 \mathrm{mg}$ & Vitamin stock & \\
\hline Arginine & 210.66 & 9.5 & $300.2 \mathrm{mg}$ & Biotin & $0.1 \mathrm{mg}$ \\
\hline Histidine & 209.6 & 5.8 & $182.4 \mathrm{mg}$ & Pantothenate & $5 \mathrm{mg}$ \\
\hline Isoleucine & 131.18 & 5.8 & $114.1 \mathrm{mg}$ & folic acid & $2 \mathrm{mg}$ \\
\hline Leucine & 131.18 & 5.8 & $114.1 \mathrm{mg}$ & nicotinic acid & $10 \mathrm{mg}$ \\
\hline Lysine & 182.6 & 5.8 & $158.9 \mathrm{mg}$ & pyridoxine & $2.5 \mathrm{mg}$ \\
\hline Methionine & 149.2 & 1.9 & $42.5 \mathrm{mg}$ & thiamine & $2.5 \mathrm{mg}$ \\
\hline Phenylalanine & 165.2 & 1.9 & $47.1 \mathrm{mg}$ & choline & $50 \mathrm{mg}$ \\
\hline Threonine & 119.1 & 5.8 & $103.6 \mathrm{mg}$ & myo-inositol & $50 \mathrm{mg}$ \\
\hline Tryptophan & 204.2 & 1.9 & $58.2 \mathrm{mg}$ & Phosphate & \\
\hline Valine & 117.1 & 5.8 & $101.9 \mathrm{mg}$ & $\mathrm{K}_{2} \mathrm{PO}_{4} \cdot 3 \mathrm{H}_{2} \mathrm{O}$ & $150 \mathrm{mg}$ \\
\hline
\end{tabular}


Table 2

820

\begin{tabular}{|c|c|c|c|c|c|c|c|c|c|c|c|c|c|c|c|}
\hline $\begin{array}{l}\text { Treatments } \\
\text { Measurements }\end{array}$ & \multicolumn{3}{|c|}{ Treatments } & & & & & & & & & & \multicolumn{3}{|r|}{ Contrasts } \\
\hline Glucose & 6 & 22.31 & $<0.0001$ & 1 & 39.71 & $<0.0001$ & 1 & 25.85 & $<0.0001$ & 1 & 1.48 & 0.2262 & 2 & 43.22 & $<0.0001$ \\
\hline Protein & 6 & 15.85 & $<0.0001$ & 1 & 84.09 & $<\mathbf{0 . 0 0 0 1}$ & 1 & 32.54 & 0.3719 & 1 & 12.01 & $<0.0001$ & 2 & 73.75 & 0.0004 \\
\hline Glycerol & 6 & 23.24 & $<0.0001$ & 1 & 67.76 & $<\mathbf{0 . 0 0 0 1}$ & 1 & 16.08 & 0.0001 & 1 & 17.82 & $<0.0001$ & 2 & 49.96 & $<0.0001$ \\
\hline Triglyceride & 6 & 3.57 & 0.0029 & 1 & 16.02 & 0.0001 & 1 & 0.55 & 0.4614 & 1 & 10.65 & 0.0015 & 2 & 7.49 & 0.0073 \\
\hline
\end{tabular}

821

822

\begin{tabular}{|c|c|c|c|c|c|c|c|c|c|c|c|c|}
\hline \multirow{3}{*}{ Measurements } & \multicolumn{12}{|r|}{ Contrasts } \\
\hline & \multicolumn{3}{|r|}{$\mathrm{C}_{3}-\mathrm{P}-\mathrm{R}_{3}$} & \multicolumn{3}{|r|}{$\mathrm{C}_{3}-\mathrm{P}$} & \multicolumn{3}{|r|}{$\mathrm{C}_{3}-\mathrm{R}_{3}$} & \multicolumn{3}{|r|}{$\mathrm{P}-\mathrm{R}_{3}$} \\
\hline & D.F & F- Value & P-Value & D.F & F- Value & P-Value & D.F & F- Value & P-Value & D.F & F- Value & P-Value \\
\hline $\mathrm{CO}_{2}$ & 2 & 0.48 & 0.62 & 1 & 0.07 & 0.967 & 1 & 4.65 & 0.481 & 1 & 3.55 & 0.312 \\
\hline $\mathrm{H}_{2} \mathrm{O}$ & 2 & 3.61 & 0.04 & 1 & 11.24 & 0.012 & 1 & 17.69 & 0.005 & 1 & 0.73 & 0.872 \\
\hline $\mathrm{CT}_{\max }$ & 2 & 1.63 & 0.127 & 1 & 3.61 & 0.759 & 1 & 0.09 & 0.059 & 1 & 2.54 & 0.113 \\
\hline
\end{tabular}

